\title{
Knowledge, Attitude and Behaviour Towards Recommended Vaccines Among Medical Students in Multan, Pakistan.
}

Abdul Mannan Mustafa ( $\square$ abdulmannan100598@gmail.com )

$\mathrm{CMH}$ Institute of Medical Sciences, Multan

Anika Zainab

$\mathrm{CMH}$ Institute of Medical Sciences, Multan

Muhammad Haroon ul Rasheed

$\mathrm{CMH}$ Institute of Medical Sciences, Multan

Ahmed Bilal

$\mathrm{CMH}$ Institute of Medical Sciences, Multan

Wajid Hussain Barki

$\mathrm{CMH}$ Institute of Medical Sciences, Multan

Ghulam Mustafa

Nishtar Medical University, Multan

Usama Khar

$\mathrm{CMH}$ Institute of Medical Sciences, Multan

\section{Research Article}

Keywords: Immunisation, Practices, KAP, Vaccines, Healthcare workers

Posted Date: February 15th, 2022

DOI: https://doi.org/10.21203/rs.3.rs-1359322/v1

License: (c) (1) This work is licensed under a Creative Commons Attribution 4.0 International License.

Read Full License 


\section{Abstract \\ Objective}

To evaluate the knowledge, attitude and behavior of medical students towards recommended vaccines.

\section{Method}

A cross sectional study was done, where 3000 students from medical colleges of Multan were included by convenience sampling. They filled a well-developed, pretested questionnaire through Google forms and the results were analyzed by the Google forms itself.

\section{Results}

Mostly $(69 \%)$ think they have adequate knowledge related to vaccination and that vaccines are effective for prevention (93\%) of diseases. Almost $82 \%$ were of the opinion that vaccines are safe. Mostly $(83 \%)$ believe that benefits of vaccines are greater. Majority $(86 \%)$ think the unvaccinated people are at risk. Only $25 \%$ said they trust the information regarding vaccines acquired from society. Most (91\%) think that one should get vaccinated according to the recommended vaccination plan and even $86 \%$ said one should get vaccinated even if it is not free. Some (59\%) said the route of administration matters. Majority (68\%) think there should be an aggressive law enforcement action to get vaccinated. Almost all of them (93\%) think that medical students should persuade others for vaccination and $83 \%$ of them agreed that they'd consider to take part in any campaign/ program for vaccination.

\section{Conclusion}

It has been found that medical students from all years have sufficient knowledge related to vaccination and show a positive attitude towards vaccination. Medical students can be used as a means for spreading awareness regarding infectious diseases and their prevention. We recommend medical institutes conduct workshops and introduce programs that can help to educate students on infectious diseases and vaccination.

\section{Introduction}

Immunisation is a method in which a person is made resistant to an infectious disease, usually by administering a vaccine. $\mathrm{CDC}$ recommends vaccines as an important factor in infection control, by achieving lifetime immunity via a course stretching from childhood till adulthood (; WHO, ; Wicker et al., 2008). Due to a failure to follow the recommended vaccine schedule, a greater percentage of adults die from vaccine-preventable diseases, resulting in more unnecessary suffering and a higher mortality rate. Adults are more likely than children to die from vaccine-preventable diseases in the United States, with 
approximately 50,000 adults dying from vaccine-preventable diseases each year (WHO, ; 2001). For Pakistan, the CDC and WHO recommend vaccinations for the following diseases: Measles, Mumps, Rubella, Tetanus, Diphtheria and Pertussis, Chickenpox, Shingles, Pneumonia, Influenza, Meningitis and Hepatitis B (SZILAGYI et al., 2005; Waris Qidwai et al., 2006).

Medical students who are in their clinical years and health care workers are exposed to infectious materials like blood, droplets and other body fluids. The exposure puts them at high risk and they must be protected (Zaki et al., 2018). It is of utmost importance that people who belong to the healthcare field which includes medical students, they should get vaccinated because they are not only at higher risk of getting infection but they can also transmit the infection to other patients (2020).

The healthcare force including medical students has a key role in persuading parents to get their children vaccinated. Therefore, it is essential for medical students to have adequate knowledge of the potential benefits and dangers of vaccination so that they can easily address parental concerns in the future (Muhammad Umair Khan et al., 2015). Leask et al. (Fergus et al., 2018) have shown that physicians are considered the most preferred and trusted source of information about vaccines. They play a crucial role in determining parental vaccination consent. Hence, we believe that medical students as future physicians, have a significant ability to influence the general public to lead to health safety with the use of vaccination, must be evaluated for their knowledge, attitude and practice regarding vaccination.

A recent study conducted in France demonstrated that one-third of the medical students had inadequate knowledge of vaccination and there was no optimal teaching method to teach medical students about vaccinations. Research has recognized a considerable educational gap that exists when it comes to preparing medical students and physicians to tackle clinical and ethical debate regarding vaccine hesitancy. Efforts are being done to bridge these gaps and prepare medical students during medical school to face these challenges (Cvjetkovic et al., 2017).

Health care workers are an important source of knowledge for parents and community regarding vaccines (Zaki et al., 2018). Some regard health care workers as the single most significant factor in the decision leading up to the vaccination of theirs and their child's vaccination (Taddei et al., 2014). The inability of a health care provider to recommend vaccines to patients is a significant obstacle to vaccination. According to a survey, the single most significant factor that influenced elderly people to get influenza vaccine was their doctor's recommendation. According to another study, doctors who do not recommend vaccines put the elderly at a higher risk of getting influenza and pneumonia. The lack of proper knowledge among doctors was a key factor in low incidence of vaccination among adults (2001). A survey in 2007 displayed that $75-80 \%$ participants admitted that they would get vaccines if their doctors recommended it (WHO, ). Proper knowledge and positive attitude towards vaccines by doctors should couple together in a successful promotion for immunisation (Taddei et al., 2014). We have conducted this study to determine the knowledge, attitude and behaviour of medical students as future Health care workers about vaccination so that this can help in creating workshops for vaccination awareness 


\section{Methods}

This cross-sectional study was conducted among all medical students of four medical colleges of Multan from June 2020 till February 2021. There are four medical colleges in Multan including both private and public sector. Medical Students of all four institutes agreed to participate in the study. The institutions included were Nishtar Medical University, Multan Medical and Dental College, Bakhtawar Amin Medical College and CMH Multan Institute of Medical Sciences.

\section{Data Collection Tool:}

The questionnaire was developed by a team of experts that consisted of physicians, professors and psychologists. The questionnaire was validated in a pilot study before actual data collection. The questionnaire had two parts. The first part addressed participant's demographics (Age, gender, residence, year of study and medical school name) and the second part addressed knowledge (6 questions), attitude and behavior (8 questions) towards recommended vaccines.

The questionnaire was sent to the medical students studying in the medical colleges of Multan via WhatsApp and Email. Students were approached by their respective WhatsApp class groups and Email addresses.

\section{SAMPLE SIZE:}

In Multan's medical institutes, 3000 pre-clinical and clinical year medical students are enrolled. The study took into account all of these students. Raosoft sample size calculator was used to figure out the sample sizeE. The sample size was 341 in order to achieve a $95 \%$ confidence level, a margin of error of $5 \%$, a response distribution of $50 \%$, and a population size of 3000 in the survey. To enhance the study's validity and reliability, the goal was to approach as many students as possible.

\section{INCLUSION CRITERIA AND EXCLUSION CRITERIA:}

All the medical students of all years studying in the medical colleges of Multan were included and asked to fill out the questionnaire. Only those students who wished to not submit the questionnaire were excluded from the study.

\section{ETHICAL APPROVAL:}

The data was collected according to the institutional and national ethical guidelines. Anonymity and confidentiality of the participants were ensured. The study was performed after getting the ethical approval from Institutional Review Board of CMH Multan Institute of Medical Sciences.

\section{Results}


A total of 400 students responded to this study. There were 187 (46.75\%) males and 213 (53.25\%) females. Year wise ratio of males and females is listed in the Table 1. The range of age was 17 to 26 years, whose average was 21 years. It constitutes students from both, pre-clinical and clinical years of medicine.

\section{Knowledge:}

Regarding the knowledge of vaccination, according to Table 2, which illustrates the results, most of them $(69 \%)$ think they have adequate knowledge related to vaccination. When asked if the vaccines effective for prevention of diseases majority (93\%) of them said yes. Almost $82 \%$ were of the opinion that vaccines are safe for public use. Mostly (83\%) believe that benefits of vaccines are greater than its risk. While answering the question about the people who aren't vaccinated, $86 \%$ of them believe that those people are at considerable risk. About the information regarding vaccines acquired from society, only $25 \%$ said they trust while $52 \%$ said they don't trust that information.

\section{Attitude and Behavior:}

Concerning attitude and behavior towards the vaccination and vaccination campaigns, the result are shown in Table 3. Most of them (91\%) think that one should get vaccinated according to the recommended vaccination plan. According to $81 \%$ students one should be willing to visit any hospital or vaccination center for vaccination and $86 \%$ said one should get vaccinated even if it is not free of cost. Regarding the effect of route of administration, only some (59\%) of them said it matters while few (24\%) said it doesn't matter. When asked that if there should be an aggressive law enforcement action against an infectious person, who's not getting vaccinated, majority (68\%) said yes. While answering about the vaccination of medical students, most of them (88\%) think they should get vaccinated and $93 \%$ think that medical students should persuade others for vaccination but $83 \%$ of them agreed that, if there'll be any, they'd consider to take part in any campaign/ program for vaccination.

For the question asked for future perspective, $87 \%$ clearly said that they think there should be vaccines, for newer diseases, added in recommended vaccination plan.

\section{Discussion}

Our study focuses on the knowledge, attitudes, and practices of medical students in Multan, Pakistan, in relation to recommended vaccines. We used multiple choice and narrow ended questions in the questionnaire because they improve response rates and are simple to answer (2020). Medical students, as future healthcare workers, have a significant impact on whether or not parents vaccinate their children. In a survey done in South India, parents said the most crucial factor contributing in their child's influenza vaccine decision was a doctor's recommendation (Muhammad Umair Khan et al., 2015). 
Our findings show that only $70 \%$ of students believe they have adequate knowledge, which is consistent with the findings of another regional study, which found that $75 \%$ of students knew about vaccines (Fergus et al., 2018). The Nepalian study even showed only $50 \%$ has good knowledge for vaccines (Cvjetkovic et al., 2017) and Canadian study showed low immunisation knowledge of healthcare workers (Pavlopoulou et al., 2009). In the study more than $80 \%$ medical students correctly answered the questions regarding vaccine knowledge. Similar results can be seen in the studies took place in Cameroon (97\%) and Ethiopia (85\%) (Taddei et al., 2014; Schmid et al., 2004).

In the study majority of the students ( $82 \%$ ) believe that vaccine is safe but it is a major concern for healthcare workers in Canada and USA and plays a role in low immunisation rate there (Pavlopoulou et al., 2009). While the study in Uganda says that safety concern in caretakers are due to lack of proper information (Mir et al., 2012) In terms of vaccine cost, the medical students in the study agreed that everyone should get vaccinated, even if it is not free. In a study published in Poland, medical students believe that cost plays a minor role in immunisation percentages. Contrary to that, the healthcare students in Lao (2020) and Nepal (Cvjetkovic et al., 2017) consider expensive vaccines in low income countries is a major factor for low immunisation status.

Medical students, as members of the healthcare system, are highly susceptible to all infectious diseases; therefore, the majority of them (88 percent) believe that medical students should be vaccinated on time. This result is significantly higher than the other regional study, which found that only $60 \%$ of medical students acknowledged the human papillomavirus vaccine (Fergus et al., 2018) But the reality is different as the studies show only 57\% medical students in Mirpurkhas (Tuckerman et al., 2015) and $37 \%$ medical students in Nepal (Cvjetkovic et al., 2017) were vaccinated for Hepatitis B.

Almost all of them (91\%) agreed that medical students should play a part in persuading family and friends to get vaccinated as per the advice of health authorities similar to the previous studies in Pakistan (La Torre et al., 2017) and other countries (Fergus et al., 2018).

In terms of vaccine knowledge, safety, and acceptance, the results of studies conducted in developing countries and developed countries are strikingly similar. It has been observed that people in developing countries are more accepting of vaccines and have a better understanding of them, possibly as a result of the numerous vaccination campaigns currently underway in these countries. Regardless of region or country development, all studies on immunization indicate that more emphasis on immunization should be placed in medical curriculum and study years so that medical students gain adequate knowledge, attitudes, and practices pertaining vaccines. (2020; Fergus et al., 2018; Pavlopoulou et al., 2009; Mir et al., 2012; Tuckerman et al., 2015; La Torre et al., 2017).

\section{Conclusion}

It has been found that medical students from all years have sufficient knowledge related to vaccination and show a positive attitude towards vaccination. Medical students can be used as a means for spreading awareness regarding infectious diseases and their prevention. We highly recommend medical 
institutes conduct workshops and introduce educational programs that can help to educate medical students on infectious diseases and vaccination.

\section{Declarations}

Funding: Funding was done by the authors themselves.

Conflicts of interest/Competing interests: The authors declare no financial or any conflict of interest.

Ethics approval: Ethical approval was obtained from Institutional Review Board of CMH Multan Institute of Medical Sciences.

Consent to participate: Consent was taken in the start of the questionnaire, whoever consented participated.

Consent for publication: N/A

Availability of data and material: Yes

Code availability: N/A

\section{Tables}

Table 1: No. of students according to year and gender. 


\begin{tabular}{|c|c|c|c|}
\hline Year & Gender & Number & Percentage \\
\hline \multirow[t]{2}{*}{ First year } & Males & 44 & $55 \%$ \\
\hline & Females & 36 & $45 \%$ \\
\hline \multirow[t]{2}{*}{ Second year } & Males & 41 & $46 \%$ \\
\hline & Females & 48 & $54 \%$ \\
\hline \multirow[t]{2}{*}{ Third year } & Males & 40 & $39 \%$ \\
\hline & Females & 63 & $61 \%$ \\
\hline \multirow[t]{2}{*}{ Fourth year } & Males & 36 & $47 \%$ \\
\hline & Females & 41 & $53 \%$ \\
\hline \multirow[t]{3}{*}{ Final year } & Males & 26 & $51 \%$ \\
\hline & Females & 25 & $49 \%$ \\
\hline & Males & 187 & $47 \%$ \\
\hline Total & Females & 213 & $53 \%$ \\
\hline
\end{tabular}

Table 2: Result of Knowledge based questions

\begin{tabular}{|c|c|c|c|c|}
\hline $\begin{array}{l}\text { Sr. } \\
\text { No. }\end{array}$ & Questions & YES & NO & $\begin{array}{l}\text { DON'T } \\
\text { KNOW }\end{array}$ \\
\hline 1 & $\begin{array}{l}\text { Do you think that you have adequate knowledge related to } \\
\text { vaccination? }\end{array}$ & $\begin{array}{l}276 \\
(69 \%)\end{array}$ & $\begin{array}{l}73 \\
(18 \%)\end{array}$ & $51(12 \%)$ \\
\hline 2 & $\begin{array}{l}\text { Do you think that the vaccines are effective for the prevention of } \\
\text { diseases? }\end{array}$ & $\begin{array}{l}373 \\
(93 \%)\end{array}$ & $17(4 \%)$ & $10(2 \%)$ \\
\hline 3 & In your opinion, are vaccines safe for public use? & $\begin{array}{l}329 \\
(82 \%)\end{array}$ & $37(9 \%)$ & $34(8 \%)$ \\
\hline 4 & $\begin{array}{l}\text { Do you believe that the benefits of the vaccine are greater than the } \\
\text { risks it carries? }\end{array}$ & $\begin{array}{l}335 \\
(83 \%)\end{array}$ & $29(7 \%)$ & $36(9 \%)$ \\
\hline 5 & $\begin{array}{l}\text { Do you believe that people who are not vaccinated are at a } \\
\text { considerable risk? }\end{array}$ & $\begin{array}{l}345 \\
(86 \%)\end{array}$ & $34(8 \%)$ & $21(5 \%)$ \\
\hline 6 & $\begin{array}{l}\text { Do you trust the information regarding vaccines that is acquired } \\
\text { from the society? }\end{array}$ & $\begin{array}{l}101 \\
(25 \%)\end{array}$ & $\begin{array}{l}209 \\
(52 \%)\end{array}$ & $90(22 \%)$ \\
\hline
\end{tabular}

Table 3: Result of Behavior and Attitude based questions 


\begin{tabular}{|c|c|c|c|c|}
\hline $\begin{array}{l}\text { Sr. } \\
\text { No. }\end{array}$ & Questions & YES & NO & $\begin{array}{l}\text { DON'T } \\
\text { KNOW }\end{array}$ \\
\hline 1 & $\begin{array}{l}\text { Do you think, one should consider getting vaccinated according to the } \\
\text { recommended vaccination plans by health authorities? }\end{array}$ & $\begin{array}{l}365 \\
(91 \%)\end{array}$ & $\begin{array}{l}18 \\
(4 \%)\end{array}$ & $\begin{array}{l}17 \\
(4 \%)\end{array}$ \\
\hline 2 & $\begin{array}{l}\text { Would one be willing to visit any hospital or vaccination center to get } \\
\text { vaccinated? }\end{array}$ & $\begin{array}{l}327 \\
(81 \%)\end{array}$ & $\begin{array}{l}40 \\
(10 \%)\end{array}$ & $\begin{array}{l}33 \\
(8 \%)\end{array}$ \\
\hline 3 & Do you think one should go for vaccination even if it's not free of cost? & $\begin{array}{l}345 \\
(86 \%)\end{array}$ & $\begin{array}{l}30 \\
(7 \%)\end{array}$ & $\begin{array}{l}25 \\
(6 \%)\end{array}$ \\
\hline 4 & $\begin{array}{l}\text { Do you think the route of vaccine administration (oral, IV, IM etc) influences } \\
\text { the decision to receive a vaccine? }\end{array}$ & $\begin{array}{l}238 \\
(59 \%)\end{array}$ & $\begin{array}{l}97 \\
(24 \%)\end{array}$ & $\begin{array}{l}65 \\
(16 \%)\end{array}$ \\
\hline 5 & $\begin{array}{l}\text { Do you think it is necessary for medical students to get vaccinated before } \\
\text { coming in contact with/treating infected patients? }\end{array}$ & $\begin{array}{l}355 \\
(88 \%)\end{array}$ & $\begin{array}{l}25 \\
(6 \%)\end{array}$ & $\begin{array}{l}20 \\
(5 \%)\end{array}$ \\
\hline 6 & $\begin{array}{l}\text { Will you consider aggressive law enforcement action against an infectious } \\
\text { person not getting vaccinated?] }\end{array}$ & $\begin{array}{l}274 \\
(68 \%)\end{array}$ & $\begin{array}{l}65 \\
(16 \%)\end{array}$ & $\begin{array}{l}61 \\
(15 \%)\end{array}$ \\
\hline 7 & $\begin{array}{l}\text { Do you agree that the medical students should persuade others to go for } \\
\text { vaccination? }\end{array}$ & $\begin{array}{l}364 \\
(91 \%)\end{array}$ & $\begin{array}{l}19 \\
(4 \%)\end{array}$ & $\begin{array}{l}17 \\
(4 \%)\end{array}$ \\
\hline 8 & $\begin{array}{l}\text { In case you ever get a chance to be a part of a vaccination campaign/program } \\
\text { in future, will you consider it? }\end{array}$ & $\begin{array}{l}334 \\
(83 \%)\end{array}$ & $\begin{array}{l}23 \\
(5 \%)\end{array}$ & $\begin{array}{l}43 \\
(10 \%)\end{array}$ \\
\hline 9 & $\begin{array}{l}\text { Do you think that in the future, newer diseases ought to be included in the } \\
\text { CDC(centres for disease control and prevention) vaccination program? }\end{array}$ & $\begin{array}{l}348 \\
(87 \%)\end{array}$ & $\begin{array}{l}14 \\
(3 \%)\end{array}$ & $\begin{array}{l}38 \\
(9 \%)\end{array}$ \\
\hline
\end{tabular}

\section{References}

Raosoft Sample Size. http://www.raosoft.com/samplesize.html怄

WHO/ CDC vaccines for Pakistan. https://www.passporthealthusa.com/destination-advice/pakistan/怄

(2001). Hepatitis B and the health care worker-WHO. , 50, 232-2522.

(2020). Adult Immunization_ The Need for Enhanced Utilization _ American Council on Science and Health. , 姆

Cvjetkovic, S. J., Jeremic, V. L., \& Tiosavljevic, D. V. (2017). Knowledge and attitudes toward vaccination: A survey of Serbian students. Journal of infection and public health, 10(5), 649-656.

https://doi.org/10.1016/j.jiph.2017.05.008怄

Fergus, E., Speare, R., \& Heal, C. (2018). Immunisation Rates of Medical Students at a Tropical Queensland University. Tropical Medicine and Infectious Disease, 3(2), 52-52.

https://doi.org/10.3390/tropicalmed3020052眈

La Torre, G., Scalingi, S., Garruto, V., Siclari, M., Chiarini, M., \& Mannocci, A. (2017). Knowledge, Attitude and Behaviours towards Recommended Vaccinations among Healthcare Workers. Healthcare, 5(1), 1313. https://doi.org/10.3390/healthcare5010013怄 
Mir, O., Adam, J., Gaillard, R., Gregory, T., Veyrie, N., Yordanov, Y., Berveiller, P., Chousterman, B., \& Loulergue, P. (2012). Vaccination coverage among medical residents in Paris, France. Clinical Microbiology and Infection, 18(5), E137-E139. https://doi.org/10.1111/j.1469-0691.2012.03788.x怄

Muhammad Umair Khan, Akram Ahmad, Talieha Aqeel, Naila Akbar, Saad Salman, \& Jawaria Idress (2015). A Cross-Sectional Survey of Healthcare Workers on the Knowledge and Attitudes towards Polio Vaccination in Pakistan. , 10(10), 42-42. https://doi.org/10.1371/journal怄

Pavlopoulou, I. D., Daikos, G. L., Tzivaras, A., Bozas, E., Kosmidis, C., Tsournakas, C., \& Theodoridou, M. (2009). Medical and Nursing Students with Suboptimal Protective Immunity against Vaccine-Preventable Diseases. Infection Control \& Hospital Epidemiology, 30(10), 1006-1011. https://doi.org/10.1086/605923四

Schmid, K., Wallaschofski, H., \& Drexler, H. (2004). Student health policy of a German medical schoolresults of a cross sectional study concerning students' immunity to vaccine-preventable diseases. Int $J$ Hyg Environ Health, 207(6), 595-600. https://doi.org/10.1078/1438-4639-00333四

SZILAGYI, P., SHONE, L., BARTH, R., KOUIDES, R., LONG, C., HUMISTON, S., JENNINGS, J., \& BENNETT, N. (2005). Physician practices and attitudes regarding adult immunizations. Prev Med, 4O(2), 152-161. https://doi.org/10.1016/j.ypmed.2004.05.010怄

Taddei, C., Ceccherini, V., Niccolai, G., Porchia, B. R., Boccalini, S., Levi, M., Tiscione, E., Santini, M. G., Baretti, S., Bonanni, P., \& Bechini, A. (2014). Attitude toward immunization and risk perception of measles, rubella, mumps, varicella, and pertussis in health care workers working in 6 hospitals of Florence, Italy 2011. Human Vaccines \& Immunotherapeutics, 10(9), 2612-2622.

https://doi.org/10.4161/21645515.2014.970879هष甘

Tuckerman, J. L., Collins, J. E., \& Marshall, H. S. (2015). Factors affecting uptake of recommended immunizations among health care workers in South Australia. Human Vaccines \& Immunotherapeutics, 11(3), 704-712. https://doi.org/10.1080/21645515.2015.1008886怄

Waris Qidwai, Syed Sohail Ali, Semi Ayub, \& Salma Ayub (2006). KNOWLEDGE, ATTITUDE AND PRACTICE REGARDING IMMUNIZATION AMONG FAMILY PRACTICE PATIENTS. , 1, 15-19.凶UX

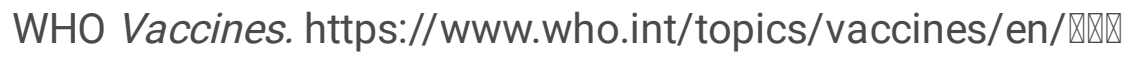

Wicker, S., Allwinn, R., Gottschalk, R., \& Rabenau, H. F. (2008). Reliability of medical students' vaccination histories for immunisable diseases. BMC Public Health, 8(1), 373-373. https://doi.org/10.1186/14712458-8-121怄区

Zaki, S., Usman, A., Tariq, S., Shah, S., Azam, I., Qidwai, W., \& Nanji, K. (2018). Frequency and Factors Associated with Adult Immunization in Patients Visiting Family Medicine Clinics at a Tertiary Care Hospital, Karachi. Cureus, 10(1), e2083. https://doi.org/10.7759/cureus.2083眈 